\title{
Uma Perspectiva Católica da Psicologia no Brasil: Análise de Artigos da Revista “A Ordem”*
}

\author{
A Catholic Perspective of Psychology in Brazil: Analysis of Articles taken from "A Ordem" Magazine
}

Ana Maria Jacó-Vilela ${ }^{\mathrm{I}}$

Luiz Fellipe Dias da Rocha ${ }^{\mathrm{I}}$

\section{Resumo}

O texto analisa como os intelectuais católicos perceberam e enfrentaram a emergência da psicologia científica no Brasil entre 1920 e 1960 . Foi utilizada como fonte a revista "A Ordem", criada em 1921 por componentes desse grupo com vistas a recuperar a hegemonia da Igreja Católica no País. Fez-se o levantamento dos textos publicados nas décadas citadas, por meio de seleçáo e análise daqueles que pudessem tratar de temas psicológicos. Embora o conteúdo moral esteja constantemente presente, bem como uma defesa da psicologia tomista, há uma mudança de tom entre os anos iniciais, de forte crítica à psicologia científica, e a década de 1960, quando se reconhece a existência de uma ciência que, por sua vez, deve respeitar e não se opor às verdades católicas.

Palavras-chave: Psicologia; Igreja Católica; moral.

\section{Abstract}

The text looks at how catholic intellectuals realized and faced the emergence of scientific psychology in Brazil between 1920 and 1960 . The source was "A Ordem" magazine, created in 1921 by members of that group aiming to recover the hegemony of the Catholic Church in the country. A survey of articles published between decades referred before was made, through selecting and analyzing those which could have something to do with psychological themes. The moral content is constantly present, although in the 1920s Thomism appear as the only possibility to explain psychic powers, and later, to acknowledge the existence of a science which, in turn, must respect and not to oppose the catholic truths.

Keywords: Psychology; Catholic Church; morality.

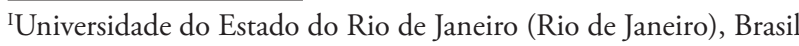

Este trabalho teve por objetivo analisar a relação da Igreja Católica com a psicologia no Brasil, especificamente como aquela encarou a emergência do campo psicológico entre as décadas de 1920 e 1960.

A escolha desse tema decorreu de nosso interesse em melhor contextualizar o desenvolvimento da psicologia no Brasil. A constataçáo de que os primeiros cursos de psicologia no país foram criados em instituições católicas ${ }^{1}$ antes da regulamentação da profissão e dos cursos, vinte anos após um artigo publicado em "A Ordem" (Athayde, 1932), que foi considerado um dos motivos do fechamento do que seria o primeiro curso de psicologia no Brasil (Centofanti, 1982), levou nosso grupo de pesquisa a indagar o porquê desse investimento católico institucional na psicologia. Uma investigação está terminada (Lobato, 2013), outra, em fase de finalização (Ferraz, 2014). Com o motivo adicional do artigo citado acima, uma terceira investigação foi conduzida tendo como fonte a revista "A Ordem", sobre a qual discorreremos mais

\footnotetext{
As instituiçóes que criaram cursos de Psicologia antes da regulamentação da profissão e dos cursos em 1962 foram: PUC-Rio (1953), PUC-RS (1954), USP (1957), Puc-MG (1959) e UNICAP (1961), ou seja, quatro foram criados em instituições católicas.
}

adiante. Para isso, faz-se necessário nos estendermos um pouco sobre a história da Igreja Católica no País, notadamente no século XIX, para melhor compreensão das condições de emergência dessa revista.

Sabemos que a Igreja Católica está presente no Brasil desde a chegada dos portugueses. Os clássicos estudos de Gilberto Freyre (1933/2000), Sérgio Buarque de Holanda (1936/1969) e Caio Prado Júnior (1942/1989) são apenas alguns exemplos da farta literatura que tão bem analisou os efeitos da colonização portuguesa e, ao mesmo tempo, católica no País. Esta ocorreu principalmente por intermédio dos jesuítas que, comandados pelo padre Manuel da Nóbrega, chegaram na armada do primeiro governador geral do Brasil, Tomé de Souza, em 1549. Membros da ordem religiosa Companhia de Jesus, criada no contexto da Contrarreforma como meio de oferecer resistência ao avanço do protestantismo no mundo europeu, deviam total obediência à doutrina da Igreja Católica e ao papa e tinham como missão, nessas terras recém-descobertas, a catequização dos índios transmitir-lhes a língua portuguesa, os costumes europeus e a religiáo católica —-, contribuindo assim para a unificação da colônia com base na religião e 
na obediência à Coroa. O estudo dos padres jesuítas, que utilizavam a teologia tomista para melhor entender o funcionamento das faculdades da alma, permitiu a construçáo de um modo de pensamento que veio a ser considerado, no século XX, como uma psicologia dos indígenas, com "ideias" ou "saberes psicológicos" preexistentes à psicologia científica (Massimi, 2007).

Embora não fosse a única ordem religiosa presente no Brasil, e, certamente, as demais ordens tenham contribuído fortemente para o que diferentes autores apontam como impregnação da cultura ocidental pelo cristianismo (Mendieta \& Van Antwerpen, 2011), é somente sobre os trabalhos jesuíticos que conhecemos estudos específicos atribuindo-lhes relevância na constituição dos saberes psicológicos, razão de seu destaque neste texto.

Fausto (1995) relata que a Igreja Católica detinha forte influência no cenário político e intelectual português na época das grandes navegaçóes. Assim, as caravelas lusitanas levavam, além de homens e equipamentos, também uma religião. Essa presença pode ser percebida na famosa - e pouco lida até recentemente, pois os livros didáticos não a traziam — carta de Pero Vaz de Caminha ao rei D. Manuel. Nesta, o autor declara ser Deus o responsável pela presença portuguesa no novo território, com o objetivo de salvar os índios por meio da fé católica:

Parece-me gente de tal inocência que, se nós entendêssemos a sua fala e eles a nossa, seriam logo cristáos, visto que não têm nem entendem crença alguma, segundo as aparências. E, portanto se os degredados que aqui hão de ficar aprenderem bem a sua fala e os entenderem, náo duvidam que eles, segundo a santa tenção de Vossa Alteza, se farão cristáos e hão de crer na nossa santa fé, à qual praza a Nosso Senhor que os traga, porque certamente esta gente é boa e de bela simplicidade. E imprimir-se-á facilmente neles qualquer cunho que lhe quiserem dar, uma vez que Nosso Senhor lhes deu bons corpos e bons rostos, como a homens bons. E o Ele nos para aqui trazer creio que não foi sem causa. E, portanto Vossa Alteza, pois tanto deseja acrescentar a santa fé católica, deve cuidar da salvaçáo deles. E prazerá a Deus que com pouco trabalho seja assim! (Caminha, 1500, pp. 11-12).
A presença e influência do catolicismo continuaram nos períodos conhecidos como Brasil Colônia e Vice-Reinado (1500-1822). Entretanto, a Igreja sofreu um grande abalo em 1759, quando o entáo secretário de Estado do Reino de Portugal, Marquês de Pombal, decretou a expulsão dos jesuítas do território português e, consequentemente, de suas colônias, pois considerava que representavam um obstáculo ao projeto de modernização iluminista do Estado português (Fausto, 1995).

Isso não impediu que o catolicismo continuasse presente e forte no País, com outras ordens e com os padres seculares; como dito antes, ele já estava ancorado na cultura brasileira. Assim, foi possível que, na Constituição de 1824, promulgada pelo recente Império Brasileiro, o catolicismo se tornasse a religião oficial do País, o que estabeleceu uma relação formal entre a Igreja e a Coroa. Ao Imperador era facultado o direito ao padroado (prerrogativa de preencher os cargos eclesiásticos mais importantes) e ao beneplácito (aprovação das ordens e bulas papais para que fossem cumpridas, ou não, em território nacional). Os próprios sacerdotes eram tratados como funcionários públicos e recebiam salários da Coroa (Serbin, 2008). Dessa forma, quando, no Segundo Reinado, o Estado se propôs a consolidar a ideia de nação, criando uma história, símbolos e identidade, a chegada dos portugueses é iconograficamente representada pelo quadro A Primeira Missa, de Victor Meirelles, de 1860.

Todavia, nesse período - último quartel do século XIX - a elite intelectual do País, a chamada "Geração 70", envolveu-se com o "bando de ideias novas" (Romero, 1900/1926) — ciência, positivismo, evolucionismo, materialismo - afastando-se da Igreja, das explicaçôes teológicas e metafísicas, segundo o julgamento comteano.

Se a cultura, como o conjunto de conhecimentos, crenças, hábitos e costumes de uma dada sociedade, é, em nosso caso, marcadamente cristã ou sincrética, como prefere Sanchis (2012) —, a partir do século XVIII, mais precisamente do XIX no Brasil, essa cultura deixa de ser englobada exclusivamente pela religião e se torna fragmentada, no sentido de Dumont (1985). Para esse autor, em sua análise acerca da constituição da "ideologia do individualismo" nas modernas sociedades ocidentais, a substituiçáo do Estado religioso pelo laico decorre, dentre outros motivos (como a mudança do modo de produção), da emergência de um modo de pensar a vida dos homens por meio de uma nova díade 
conceitual, indivíduo e sociedade, agora separadas e não mais englobadas.

Um poderoso auxílio a essa fragmentação, no caso brasileiro, ocorre ainda na década de 1870 e no âmbito das relaçóes da Igreja com o Estado. Trata-se da denominada Questáo Religiosa, um conflito que, iniciado como um enfrentamento entre a Igreja Católica e a maçonaria, se tornou uma grave questão de Estado. Iniciou-se em 1864, quando o papa Pio IX validou uma bula que determinava a excomunhão imediata de todos os católicos envolvidos com a prática da maçonaria. Entretanto, dom Pedro II, valendo-se dos poderes do padroado, estabeleceu, por decreto, não reconhecer o valor de tal ordem. Dom Vital e dom Macedo Costa - bispos de Olinda e Belém, respectivamente - , pautados na bula já desconstituída de poder em território nacional, interditaram irmandades sob sua jurisdição, por manterem em seu seio membros maçons. Julgou-se, então, que tais bispos feriram a Constituiçáo do Império e incorreram em culpa de desobediência civil. Foram presos e condenados a trabalhos forçados. Contudo, sua condenação repercutiu negativamente tanto em território nacional quanto internacional, o que desencadeou inúmeros protestos populares e respostas indignadas do papa. Diante do clamor popular e da exigência do Vaticano, dom Pedro II concedeu anistia aos bispos, que retornaram às suas respectivas dioceses (Serbin, 2008; Villaça, 2006).

Com a proclamação da República em 1889, o Estado tornou-se laico, logo, sem qualquer obrigação para com a Igreja. Vários foram os movimentos republicanos, mas seu principal propulsor foi o positivista. É essa vertente que, ao atrair inicialmente intelectuais, militares e médicos brasileiros, teve um grande papel entre nós, não somente na proclamação da República mas sobretudo no modo de organização do novo regime político (Carvalho, 1987; 1990). Carvalho demonstra, todavia, que a imobilização católica náo foi total ao analisar o embate para a escolha do símbolo feminino da República, que resultou na coroação de Nossa Senhora Aparecida como "rainha do Brasil", em 1904, apenas 15 anos após a proclamação da República. Esse episódio é mais uma demonstraçáo do hibridismo presente no imaginário brasileiro, que parece incorporar o divino e o laico, o servo e o cidadáo, a monarquia e a república (Carvalho, 1990), noção muito próxima ao sincretismo de que fala Sanchis (2012).
Com a opção intelectual pelas novas ideias europeias, notadamente o materialismo, a Questão Religiosa e a Proclamaçáo da República, ocorreu uma inconteste perda financeira e um afastamento dos meios político e intelectual em relação à Igreja. Esta se via excluída das mobilizaçóes político-sociais do começo do século XX, período marcado por forte efervescência ideológica, com a presença de organizaçóes anarquistas e sindicais, novos movimentos culturais e debate sobre a educação popular.

Segundo Sanchis (2005), foi nesse contexto que a cúpula católica desenvolveu a estratégia iniciada no século XIX e conhecida como "Reação Católica", que visava (re)conquistar o Brasil nação. Essa nova fase "tem início em 1916 com a publicação da carta pastoral de D. Sebastiáo Leme, nomeado arcebispo metropolitano de Olinda e Recife" (Velloso, 1978, p.120). Na carta, a elite do País foi convocada à reconversão para, a partir de entáo, reconverter o povo.

Esse chamado de dom Sebastiáo Leme (18821942), posteriormente cardeal arcebispo do Rio de Janeiro, foi atendido, entre outros, por dois intelectuais, Jackson de Figueiredo e Hamilton Nogueira, que idealizaram um instrumento capaz de exercer influência face àquelas transformaçôes: a revista $\mathrm{A}$ Ordem, criada em 1921. Jackson de Figueiredo (1891-1928) era sergipano, advogado e, transferindo-se para o Rio de Janeiro e em contato com dom Sebastião, tornou-se um incansável defensor da fé católica. Influenciou o médico carioca Hamilton Nogueira (1897-1981), que aderiu ao catolicismo e se tornou conhecido líder católico. A revista "A Ordem", por sua vez, discutia temas religiosos, mas, principalmente, questóes em voga no momento, como divórcio, educação etc., com base no enfoque da Igreja. Logo em sua gênese, no calor da campanha eleitoral para presidente da República, a revista denunciava a crise moral, a passividade dos católicos e o aumento das estatísticas criminais, causadas, segundo a revista, pela perda dos valores morais (católicos) em função da prevalência das ideias materialistas.

Um ano depois, em 1922, Jackson de Figueiredo fundou o Centro Dom Vital (cujo nome, lembremos, é homenagem a um dos dois bispos da crise entre Igreja e Estado no século XIX), com o objetivo de reunir "intelectuais que almejavam reagir contra o materialismo crescente da literatura e da inteligência brasileira" (Lima, 1935, citado por Schincariol, 2006, p. 97). O Centro Dom Vital tornou-se responsável pela edição da revista e fez dela seu porta-voz, como continua a ser até os dias de hoje. 
Posteriormente, a partir do Centro Dom Vital, iniciou-se um movimento para uma educaçáo superior católica, sob a liderança do padre Leonel Franca (1893$1948)^{2}$ e de Alceu Amoroso Lima (1893-1983) ${ }^{3}$. Distintas associaçóes foram criadas para esse fim, como a Associação dos Universitários Católicos (1929), o Instituto Católico de Estudos Superiores (1932) e a Confederação Católica Brasileira de Educação (1933). Em 1934, realizou-se no Rio de Janeiro o I Congresso Católico de Educação. Do Instituto Católico de Estudos Superiores surgiram os cursos de direito, geografia, história, ciências sociais, pedagogia e letras clássicas, neolatinas e neogermânicas, que permitiram a criação da Faculdade de Direito e da Faculdade de Filosofia, aglutinadas às Faculdades Católicas do Rio de Janeiro (1942). A eleição daquelas duas faculdades como "núcleos do ensino superior católico convinha ao projeto da Igreja, já que a maior parte das elites brasileiras era composta de juristas e advogados. Também interessava a disseminação da cultura humanística entre as elites, facilitando a sua espiritualização" (Centro de Pesquisa e Documentação de História Contemporânea do Brasil, 2014).

Com o acréscimo da Escola de Serviço Social às Faculdades Católicas, foi possível a transformação destas na Universidade Católica do Rio de Janeiro (1946), a qual, por sua vez, recebeu da Santa Sé o título de Pontifícia em 1947, e na qual, em 1953, foi criado o primeiro curso de psicologia do Brasil.

Vimos, pois, que a aparente derrota que a Igreja Católica sofreu no século XIX, quando os intelectuais abandonam seus princípios e recepcionam as "ideias novas" que chegam da Europa e ela perde parte de seu poder na disputa com o Estado na Questão Religiosa, é enfrentada, nas primeiras décadas do século $\mathrm{XX}$, com uma estratégia bem traçada de trazer novamente para a participação ativa na Igreja os intelectuais e, por meio deles, voltar a ocupar seu papel hegemônico na população.

Assim, se entendemos que a religião católica permeia a cultura brasileira, entendemos também que o estudo de grupos católicos específicos, como o de intelectuais, pode ser significativo, pois se constituem em polos organizadores da sociedade, produzidos e

\footnotetext{
Padre Leonel Franca publicou, em 1934, o livro "Psicologia da Fé", uma retomada do tomismo. Renomado intelectual jesuíta, foi o primeiro reitor da PUC-Rio.

Conhecido também pelo pseudônimo de Tristão de Athayde, que utilizava em suas atividades jornalísticas, Alceu Amoroso Lima era liberal de tendência conservadora que se tornou defensor da democracia durante a ditadura de 1964-1985. Crítico literário, professor, escritor, sua memória está preservada no Centro Alceu Amoroso Lima pela Liberdade, em Petrópolis.
}

produtores de valores culturais. No caso que aqui nos propusemos a estudar, ou seja, o dos intelectuais reunidos no Centro Dom Vital, nossa fonte de análise foi a revista "A Ordem", que nos pareceu possibilitar a recuperação da especificidade do pensamento católico em relação à psicologia em um determinado momento histórico.

\section{Método}

Estudamos a revista "A Ordem" no período compreendido entre sua criação (1921) e a regulamentação da profissão de psicólogo e dos cursos de psicologia no País pela lei $n^{\circ} 4119 / 62$. Nosso levantamento foi realizado na biblioteca da PUC-Rio em sua quase totalidade, por ser o local de mais fácil acesso. Recorremos à biblioteca do Centro Dom Vital somente para preencher as falhas encontradas na primeira biblioteca.

Fizemos um levantamento extensivo de todos os números, catalogando os artigos, os editoriais e as seçôes (livros e notas). Isso foi necessário porque, em seus primeiros anos, a revista não apresentava índice e porque verificamos muitos dados de interesse dispersos nas seçôes.

Nosso critério de estabelecimento de relação com a psicologia foi muito abrangente, tendo em vista que, nas primeiras décadas estudadas, esta ainda não era uma área de conhecimento e uma prática autônomas no Brasil, estando subsumida na medicina, no direito, na educação.

Criou-se uma ficha de catalogaçáo com os seguintes campos de preenchimento: data de publicação, número, título, autor, PSI (relação com a psicologia) e localização (em qual biblioteca foi feita a pesquisa). O campo PSI visava apontar se, na primeira visada, o texto tinha ou não relação com a psicologia, permitindo, portanto, as respostas $S$ (sim), N (não) ou T (talvez). Posteriormente foram lidos e resumidos $20 \%$ dos textos assinalados como $S$, sendo que, quando este total foi considerado pequeno, também foram resumidos textos assinalados como $\mathrm{T}$.

Não fizemos, todavia, dois levantamentos importantes: as condiçóes de produção da revista, aqui envolvendo tanto os redatores dos diversos textos sem assinatura quanto os recursos financeiros para sua impressão e distribuição, bem como sua tiragem e formas de distribuiçãa. Embora esses dados não sejam diretamente pertinentes ao objetivo de nossa investigação, certamente levantariam luz sobre os mecanismos de funcionamento desse braço da Igreja. 


\section{Resultados}

Observamos que a periodicidade da revista foi, ao longo do período estudado, muito irregular na primeira década, quando variou entre ser mensal, bimestral e, mesmo, trimestral. Assim, foi mensal de agosto de 1921 a outubro de 1922, de novembro de 1924 a julho de 1925, de janeiro a março de 1928 , de janeiro a junho de 1934, de janeiro a dezembro de 1941 e de janeiro a junho de 1945. Tornou-se bimestral em poucos períodos: de agosto a outubro de 1923 e de janeiro a outubro de 1924. Foi trimestral nos seguintes períodos: de janeiro a junho de 1923, de agosto de 1925 a dezembro de 1927 e de junho de 1928 a dezembro de 1930. Finalmente, adotou a semestralidade a partir de janeiro de 1931.

No que diz respeito ao preenchimento do cargo de presidente (redator-chefe), encontramos que Jackson de Figueiredo ficou de agosto de 1921 a agosto de 1928, embora tenha se afastado (por doença) e sido substituído por Hamilton Nogueira de abril de 1927 a junho de 1928. Tristáo de Athayde ficou um largo período como diretor-responsável pela revista a partir dessa data.

Nosso levantamento catalogou 478 textos na década de 1920 , dos quais 16 vinculados à psicologia; 1.682 textos na década de 1930, dos quais 64 foram classificados como atrelados à psicologia; 1.696 na década de 1940, dos quais 27 estavam ligados à psicologia; 1.474 na década de 1950, dos quais 23 vinculados à psicologia e, finalmente, 405 na década de 1960, dos quais 17 atrelados à psicologia.

Verificamos que esses textos permitem inúmeras análises de temas como a educação, principalmente a proposta da Escola Nova; a sexualidade e a convivência de casais; a vida em família e a educação dos filhos; além de trazer inúmeras resenhas de livros, entre outros tipos de textos. Pode-se também analisar a contribuição específica de um determinado autor - Massimi (2000), por exemplo, o faz em relação aos artigos de Theobaldo Miranda dos Santos relativos à educaçáo. Enfim, "A Ordem" oferece várias possibilidades em relação à psicologia. Neste artigo, optamos por analisar o modo como o pensamento dos intelectuais católicos se situa frente a essa nova ciência e as transformaçóes que surgem ao longo do período em questão.

\section{Discussão}

Uma psicologia que ameaça

"A Ordem", como dito, surgiu na década de 1920 com o objetivo de recuperar as elites que haviam aban- donado o catolicismo em prol de diferentes ideias que chegaram ao País no século XIX; é mister ter em conta que, entre estas, situava-se uma nova interpretação para as faculdades da alma, agora entendidas como fenômenos psíquicos, com base orgânica e passíveis de mensuração. Apesar de o laboratório experimental não ser a única vertente teórico-metodológica que chegara à época, sem dúvida foi a que mais causou repulsa, como relata Lourenço Filho a respeito de resposta à proposta feita em 1897 da criação do primeiro laboratório no Rio de Janeiro: "seria ridículo pretender levar as faculdades da alma à análise de aparelhos" (Lourenço Filho, 2004/1955, p. 74).

Embora houvesse recepção da psicologia científica que se desenvolvia na Europa e nos Estados Unidos, esta era feita de forma autodidata por poucos. Estes se encarregavam de propagá-la por intermédio de publicaçôes (livros, jornais) ou pelo ensino nas Escolas Normais (Jacó-Vilela, 2012). Assim, há divulgação de uma psicologia "materialista" que é contrária à psicologia tomista, a única em vigor no século XIX.

Todavia, embora discordem da nova psicologia, os autores de "A Ordem" estão atualizados com seu desenvolvimento. Citam Weber, Fechner, Wundt, Titchner, Binet e Stuart Mill. Freud é um autor presente em vários textos, desde a década de 1930, com maior frequência nas décadas de 1950 e 1960.

O texto de Barbosa (1929), intitulado "O problema da formação do pensamento", embora ainda do período inicial, talvez seja o mais representativo das preocupaçôes que norteiam a apresentação do discurso psicológico em "A Ordem" nas décadas em análise. Centra sua argumentação contra a psicologia associacionista e o funcionalismo com base no livro de Farias Brito (1862-1917), "A Base Física do Espírito", de 1912. Advogado de formaçáo, filósofo por opção e formação autodidata, como era comum no Brasil de sua época, e católico convicto, Farias Brito foi crítico ferrenho à psicologia que emergia nos países europeus nos séculos XVIII a XX, considerando-a uma "psicologia sem alma" - contrária à "psicologia dos poetas" - por seu caráter materialista e evolucionista. Seus textos, principalmente o livro citado, são constantemente utilizados pelos autores de "A Ordem" como fundamento de seus discursos.

Assim o faz Barbosa (1929) $)^{4}$, que analisa em detalhe como e onde se pode encontrar a "base física"

Cônego Florentino Barbosa (1881-1958), padre diocesano, permaneceu quase toda sua vida na Paraíba, exceto um período em que esteve no Rio de Janeiro, quando contribuiu com "A Ordem", e períodos de estudo em Roma. Filósofo com sólida formação tomista e interesse no problema do conhecimento, tema sobre o qual publicou livro em 1953, foi também historiador. 
dos fatos do espírito. Retomando Farias Brito e sua análise do empirismo baconiano do qual decorreria duas escolas associacionistas - uma psíquica, com base em Hume e cujo principal autor será Stuart Mill, seguido de James, que trabalha com fenômenos que não têm um substrato real, o que faz com que haja instabilidade dos estados da consciência, e outra fisiológica, que admite a existência da matéria e

tem a pretensão de explicar todos os phenomenos espirituaes como resultantes da evolução; ou como equivalência dos movimentos do cérebro e do systema nervoso [...] é a theoria da equipe psycho-physiologica; theoria que pretende medir os pensamentos através das reacçóes physiologicas (Barbosa, 1929, p. 155).

Barbosa (1929) procura separar os fenômenos mentais que podem ocorrer paralelamente à vida física daqueles que ocorrem isoladamente. Raciocínios e voliçóes claramente the parecem como isolados dos fenômenos físicos do cérebro, pois prescindem de imagens que poderiam ser consideradas como resultantes dos movimentos cerebrais. Não há uma explicação clara desse raciocínio, a não ser se o ligarmos a um parágrafo anterior, no qual Barbosa menciona serem os fenômenos psíquicos como "sombras" que reproduzem todos os movimentos dos fenômenos fisiológicos. Estaríamos aqui retomando o idealismo platônico? A resposta parece ser positiva, visto o artigo caminhar na demonstraçáo de uma consciência sensitiva comum aos homens e aos animais:

Inúmeras experiências teem sido feitas sobre as funçóes dos sentidos externos, tanto dos homens quantos dos brutos, e de todos eles conclue-se que há percepçóes exactas dos objetos. Os sentidos percebem integralmente tudo quanto do mundo exterior entre em comunicação com eles (Barbosa, 1929, p. 163).

Toda e qualquer impressão recebida e transmitida aos centros sensoriaes há de excitar forçosamente todo o conjunto, formando-se ahi mesmo a imagem do objeto (Barbosa, 1929, p. 164).

A consciência sensitiva é o centro de convergência deste systema, onde circulam as imagens vindas de fora, consoante os processos indicados. Cumpre, porém, não confundi-las com os pensamentos, uma vez que ellas pertencem ao campo da sensação e estes ao da inteligência [...] [a imagem] se encontra tanto no homem como no bruto, em que falta por completo o pensamento. E bastava isso para evidenciar a distincçáo entre um e outro (Barbosa, 1929, p. 165).

Detemo-nos neste texto porque nos pareceu representativo do que está presente nos demais textos do período: a psicologia tem, sim, uma contribuição a dar à compreensão do ser humano, desde que esse seu conhecimento não tenha por base perspectivas materialistas ou evolucionistas, as que sofriam maiores objeçôes naquele momento. Encontramos esse pensamento não só em Barbosa (1929), como assinalamos acima, mas também em Nogueira (1921) e em outros textos citados ao longo deste artigo.

Em "As curas milagrosas de Lourdes à luz da medicina" (1921), de Hamilton Nogueira, há uma pequena discussão sobre sugestão. Referindo-se aos "médicos materialistas" que afirmam serem as curas milagrosas causadas pela sugestão, o autor admite haver essa possibilidade nos casos de doenças não orgânicas.

Um artigo de Tristáo de Athayde, "Traços da Psicologia do povo brasileiro", de 1934, procura estabelecer diferenças entre os homens do campo e da cidade, entre os homens das diferentes regióes, para uma interpretação do homem brasileiro embasada no modo de análise da época, em que há uma suposição do "caráter" como moldado não só pela hereditariedade, mas também pelas condiçôes climáticas e geográficas. Athayde (1934) vai inovar ao afirmar a importância da formação religiosa cristã nos traços psicológicos. Assim, após explicitar o que caracteriza o brasileiro de acordo com dicotomias como o homem do litoral versus o do sertão, o da cidade versus o do campo, o do norte versus o do sul, Athayde (1934) busca as características gerais do homem brasileiro, apontando a história da colonização lusitana, que propiciou a unificaçáo de um grande território, e, em segundo lugar, aponta o lado moral e religioso:

Cristão nasceu o Brasil. Cristão educou-se. Cristáo cresceu. E os erros da sua formação ou da sua alma derivaram sempre do esquecimento momentâneo desse fato fundamental de sua história, sem o qual se torna inteligível o estudo e a compreensão da psicologia brasileira. Pois todos os traços que hoje en- 
contramos na psicosíntese do povo brasileiro, são derivados preliminarmente da sua formação religiosa (Athayde, 1934, p. 135).

"Possessão, histeria e êxtase" (1935), artigo do padre J. Nery, por sua vez, faz críticas à conclusão de Arthur Ramos em sua obra "A possessão fetichista na Bahia" (1932) de que a possessão é um surto histérico. Nery (1935) admite a existência da histeria enquanto fenômeno psíquico e considera que alguns de seus sintomas são semelhantes aos da possessão e do êxtase místico. Avalia, porém, que nesses dois últimos se verificam algumas características que não são explicáveis por aquela hipótese. Demonstrando um grande conhecimento das doutrinas sobre histeria do século XIX (Charcot, Pierre Janet), padre J. Nery utiliza o conhecimento católico como contra-argumento, reafirmando tanto a possessão demoníaca como o êxtase místico que caracteriza os santos como diferentes do quadro da histeria.

Vimos, pois, que os textos citados dialogam com o conhecimento psicológico então existente, porém apresentando, de forma às vezes contundente, o pensamento da Igreja.

Um texto diferente, com menos ênfase psicológica e cujo caráter religioso é inegável — porém com relevância fundamental para o campo da psicologia, por causa do livro do qual trata - é um artigo do então padre Helder Câmara ${ }^{5}$ sobre como entender a alma do incrédulo, para assim levá-lo a Cristo. Para cumprir tal objetivo, resenha parte da obra "Psicologia da fé" (1934), livro do padre Leonel Franca que já se encontrava em terceira edição naquele momento. Tomista convicto, Franca era rigoroso adepto do papel da inteligência, da vontade e da Graça na crença, e em seu livro as analisa em relaçáo ao ato de fé.

Câmara (1934) se detém na parte do livro em que o padre Franca se refere aos obstáculos intelectuais e morais à consecução da fé - ignorância religiosa, vícios de método, orgulho e sensualidade. Diz preferir a expressão desconhecimento da verdade católica, pois todo ser humano se mostra ignorante em algum aspecto de sua vida, assim como todo ser humano tem algum tipo de vício de método e orgulho. Para com-

Dom Helder Câmara (1909-1999), natural de Fortaleza, Ceará, bispo auxiliar do Rio de Janeiro, transferido para Recife após o golpe militar de 1964 como arcebispo de Olinda e Recife. Próximo ao integralismo nos anos de 1930, afastou-se desse movimento, norteando sua vida apostólica pela aproximaçáo com os pobres. Foi um dos fundadores da Conferência Nacional dos Bispos do Brasil (CNBB). Criou a Cruzada de São Sebastião, no Rio de Janeiro, e o Banco da Providência. Teve participaçáo ativa na linha da Igreja que defendia os perseguidos pela ditadura militar. bater o orgulho dos incrédulos, os católicos devem fazer com que estes não se sintam conduzidos à fé, mas se convençam de que, de fato, esse é o único caminho. E para combater a sensualidade, o único remédio é criar um clima de entusiasmo entre os que são puros, uma vez que, se os mais felizes forem os puros de coração, a pureza atrairá tanto ou mais do que a própria impureza. Câmara conclui afirmando que os católicos devem aprender a linguagem que ilumine sem ofuscar, arraste sem violência, comova sem artes teatrais e ensine sem tom de mestre. Ou seja, uma forte crítica ao modo como o padre Leonel Franca conduz o discurso da Graça em seu livro.

Outra relevância desse artigo é a demonstração de que "A Ordem" permitia críticas internas. No caso, trata-se de um membro ainda jovem da hierarquia católica, localizado na longínqua Fortaleza, criticando um dos autores mais proeminentes da Igreja à época, e que viria a ser reitor da Universidade Católica do Rio de Janeiro. Mais do que um grupo monolítico de redatores, parece, pois, que havia certa diversidade de pensamento, ainda que somente religioso, dentro da revista.

\section{A psicologia não mais ameaça? Os anos 1930 e a educação.}

A década de 1930 é, sem dúvida, o período em que os projetos anteriores sobre a educação se realizam. A efervescência político-ideológica e cultural dos anos 20, que levou inclusive à criaçáo de uma Universidade Popular no Rio de Janeiro, onde Manoel Bomfim teria ministrado cursos de psicologia (Aguiar, 2000), engendrou forças para a criação da Associação Brasileira de Educação, em 1926.

Entretanto, foi somente em pleno Governo Vargas que a proposta de uma escola pública, laica, gratuita e universal se alastrou, com o Manifesto dos Pioneiros da Educação (1932) e o fortalecimento do movimento da Escola Nova. As principais propostas, principalmente a do ensino laico e gratuito, iam contra os propósitos da Igreja, que visava formar sujeitos católicos, e, mesmo se dedicando a obras de caridade e, assim, fornecendo educação a crianças sem família ou de baixa renda (Ferraz, 2014), não abria mão de formar também a elite. Assim, o discurso sobre a educação tornou-se cotidiano em "A Ordem". E, da mesma forma que a Escola Nova (Lourenço Filho, 1930/2001), os católicos também consideraram a ciência e as práticas psicológicas ferramentas indispensáveis ao seu projeto pedagógico (Massimi, 2000), desde que devidamente subordinadas ao seu ideal educativo. 
Em um primeiro momento, retornou-se aos padres da Igreja para contra-argumentar ou demonstrar que nada havia de novidade no que trazia a psicologia, como Santos (1930) explica em "Santo Agostinho: suas idéias em pedagogia e psychologia": muitos dos conhecimentos tratados pela pedagogia e pela psicologia na época e que estavam sendo encarados como novidade já haviam sido expressos por aquele pensador da Igreja. Na obra "Confissóes", por exemplo, por meio dos métodos de introspecção, observação e comparação, Agostinho estabelecera importantes formulaçôes sobre o desenvolvimento da criança e os fundamentos para uma boa educação, bem como condenara os castigos e chegara à conclusão de que o interesse - a motivação - era muito importante para o ensino. Aqui se percebe uma crítica ao behaviorismo que chegava ao País.

A questão educacional, no campo da psicologia, está exposta em outro texto, já citado anteriormente: "O Instituto Official de Psicologia" (Athayde, 1932), é uma crítica ao Governo Vargas por ter transformado o Laboratório de Psicologia da Colônia de Psicopatas do Engenho de Dentro em Instituto de Psicologia, no qual funcionaria uma Escola Superior de Psicologia, destinada à formação de "psicólogos profissionais" (Centofanti, 1982). $\mathrm{O}$ texto, não assinado mas atribuído a Tristão de Athayde por ser o redator-chefe à época, argumenta que, anteriormente, a escola estava embebida na filosofia cristâ, e, naqueles dias, a pedagogia moderna incorria em erro decorrente do fato de ser, quase que necessariamente, não religiosa. O Instituto de Psicologia teria uma orientaçáo materialista sob a capa de "ciência pura" e seria responsabilidade do governo o que viesse a acontecer com a oficialização do Instituto de Psicologia, pois este deslocaria as interpretaçóes religiosas do cenário científico nacional, implicando a descristianização do indivíduo e das instituições.

Não se sabe se por conta das pressôes católicas ou se pelas pressóes médicas - também contra a criaçáo de um curso superior de formação de profissionais psicólogos - que o Instituto de Psicologia durou somente sete meses, sendo logo desativado. Paradoxalmente, como dito antes, 4 dos 5 primeiros cursos superiores de psicologia no Brasil seráo criados em instituiçóes católicas, 20 anos depois dessa malograda tentativa.

Mas a ênfase educativa continua. Com o Centro Dom Vital interessado em fornecer educação de nível superior a católicos — como visto, o Instituto Católico de Estudos Superiores, embrião da futura Universidade Católica, fora criado ainda em 1932 - um conjunto de textos publicados em "A Ordem" tem caráter didático, de explanação sobre a psicologia.

Assim, em "Será a Psychologia sciencia natural ou cultural" (1934), Euryalo Vianna Cannabrava ${ }^{6}$ expóe o desenvolvimento da psicologia, desde quando ainda aliada à filosofia até aquele momento, quando já era uma disciplina independente. Sustenta a vinculação primordial da psicologia com um sistema filosófico: "Pouco importa que essa filosofia seja theologica, scientifica ou puramente anthropologica, porque toda questáo está em que seja uma filosofia” (p. 357). Defende, todavia, que será a filosofia antropológica que fornece uma estrutura suficientemente firme às hipóteses da psicologia como ciência, em relação ao "problema psycho-physico (relaçôes da alma com o corpo), a questão da personalidade (sob o ponto de vista moral e religioso) e a natureza essencial do homem" (p. 357).

Theobaldo Miranda dos Santos ${ }^{7}$, autor muito presente em "A Ordem", em "A Educação e as Tendências Atuais da Psicologia” (1938a) busca contextualizar o estado da disciplina no cenário das ciências, salientando que a psicologia preenche dois dos critérios fundamentais para o reconhecimento científico: numero considerável de aplicação de suas teorias e crescente multiplicação de ramos especializados. Apesar de reconhecer a existência de algumas divergências metodológicas e filosóficas que fazem da psicologia um aparente caos, afirma existir uma unidade, presente no nível dos resultados experimentais. Comprova essa unidade sintetizando as principais correntes da psicologia: behaviorista, estruturalista (gestalt-theorie), essencialista (fenomenológica), psicoanalítica, caracteriológica e neotomista, apresentando suas diferenças e pontos em comum. Considera que tais correntes têm noçôes muito próximas dos postulados da psicologia tomista, como: diferença entre vida cognocitiva e apetitiva, distinção entre conhecimento sensível e intelectual, afirmação

Euryalo Vianna Cannabrava (1908-1978), mineiro de Cataguazes, faleceu no Rio de Janeiro em 1978. Advogado de formação, foi principalmente filósofo e professor de filosofia. Participou da equipe de Waclaw Radecki no Laboratório de Psicologia na Colônia de Psicopatas no Engenho de Dentro, visando transformar o Laboratório em Instituto de Psicologia (o que ocorreu em 1932).

Theobaldo Miranda dos Santos (1905-1971), formado em odontologia e farmácia em Juiz de Fora, foi essencialmente um educador. Ocupou vários cargos em instituiçóes educacionais. Publicou diversos títulos em psicologia, destinados principalmente à formação de professores. 
da unidade irredutível do espírito, negação do mecanicismo psíquico e da psicologia associacionista e psicologia como um ramo das ciências morais. Isso o leva a concluir pela derrota da ciência experimental e pela consequente vitória da psicologia tomista.

Já o artigo "A estrutura fundamental do sentimento religioso à luz da psicologia experimental" (1939) desperta o interesse porque o autor, Frei Damião Berge $e^{8}$, pretende utilizar a ciência para estudar um dado religioso: afirma ser a ciência psicológica, especialmente a experimental, o melhor recurso para se responder às questôes: o que é o sentimento religioso e qual sua estrutura fundamental? Isso porque aquela ciência tem condiçóes de entender a religião não como doutrina ou revelação divina, mas como ato ou sentimento religioso vital que produz, no homem, certos fenômenos psíquicos. $\mathrm{O}$ autor expôe resumidamente os primeiros métodos experimentais introduzidos na psicologia da religião por Karl Girgensohn, que consistem no uso de um termo evocador do sentimento religioso e o registro, em um protocolo rigoroso, da reação do paciente. Esse protocolo permite verificar uma síntese entre a função religiosa do "eu" como elemento intelectivo, entendendo como função do "eu" aqueles atos e sentimentos que nos invadem, atingindo nosso vivo interesse. O elemento intelectivo é sempre um fato ou um objeto religioso, atingido sempre como verdade, podendo ser essa cognição intelectual de natureza discursiva ou intuitiva. Ou seja, em oposição a Theobaldo Miranda dos Santos, Berge (1939) considera que o próprio sentimento religioso pode ser estudado pelo método experimental.

A psicologia adequada ao projeto educacional católico, por sua vez, foi objeto de um livro de Jaime Castiello, "Uma Psicologia Humana da Educação", publicado em 1936. Com esse mesmo título, Barreto Filho publica uma resenha do livro em 1941, enaltecendo a obra. Castiello, jesuíta mexicano, filósofo e psicólogo, é respeitado ainda hoje por esse livro, cujo caráter humanista ultrapassou os limites da Igreja Católica. Barreto Filho9 aponta que faz uma crítica severa à psicologia materialista e associacionista, mas inova ao propor um ideal "humano" de personalidade que sirva de modelo à atividade educacional. Seu objetivo é a personalidade integral, sendo que a gestalt-theorie lhe parece um profundo reencontro da

\footnotetext{
Damiāo Berge (1895-1976), frade franciscano, escreveu somente um outro texto sobre psicologia, versando sobre oração.

9 José Barreto Filho foi professor de psicologia nas Faculdades Católicas do Rio de Janeiro.
}

psicologia moderna com os fundamentos do humanismo. E é dessa psicologia que a Igreja Católica quer se aproximar ${ }^{10}$.

\section{Transformaçôes Discursivas nas Décadas de 1950 e 1960}

Apresentamos acima um artigo de Theobaldo Miranda dos Santos dentro do que denominamos contexto educacional. Santos também publicou, em "A Ordem", uma sequência de artigos versando sobre a temática do sonho: "Aspectos da psicologia do sonho" (1935), "O problema da gênese do sonho" (1938b), "O sonho e a memória" (1939), "Os fatores orgânicos e a gênese do sonho" (1940a) e "Psicologia comparada do sonho e da criança” (1940b).

São seus principais interlocutores, dos quais procura apresentar o pensamento com clareza: Pierre Janet, Havelock Ellis, Immanuel Kant (em relação às paixões), Théodore Flournoy, Jean Piaget, Henri-Louis Bergson, Théodule Ribot e Sigmund Freud. Se bem reconheça a este último o mérito de ter "reabilitado o sonho" (Santos, 1938b, p. 361), em sua argumentação valoriza muito mais as opiniôes de Janet que as de Freud. Isso aparece claramente em "Aspectos da psicologia do sonho" (1935), quando, fazendo revisão das teorias da psicologia do sonho, critica a teoria da afetividade onírica de Freud, segundo a qual existiria uma correlação entre o estado afetivo da vigília e o conteúdo representativo dos sonhos. Para isso, utiliza-se de argumentos de autores diversos, como Janet e Kant, bem como outras perspectivas teóricas que aproximam a atividade onírica dos instintos primários, admitindo alguma verdade nessas teorias.

Seus textos "O problema da gênese do sonho" (1938b) e "O sonho e a memória" (1939) são autorais, diferentemente dos demais, em que se guia por diferentes autores. Nesses dois, analisa a gênese do sonho (se de natureza somática ou psíquica) e contrapôe o psiquismo da vigília ao do sonho. Conclui ser o sonho influenciado por fatores fisiológicos e psicológicos e que a memória e a imaginação são os elementos preponderantes da formação das imagens oníricas (Santos, 1938b).

A presença da temática do sonho em cinco artigos, embora o referencial privilegiado não seja o psicanalítico e haja uma crítica presente à análise

\footnotetext{
10 A aproximação ocorrerá por meio da teoria rogeriana nos anos 50 e 60. No Brasil, um dos seus grandes divulgadores foi Padre Benkö (1920-2014), jesuíta húngaro que coordenou o curso de psicologia da Puc-Rio.
} 
freudiana, faz pensar sobre a relevância dessa teoria no campo das relaçóes entre a psicologia e a religião católica naquele momento.

Encontramos assim a resenha do livro "A doutrina de Freud”, de padre Antônio D’Almeida Morais Jr. (1943), na qual se destaca que, ao mostrar os limites da psicanálise, o livro é útil "aos que lutam contra a ignorância de alguns fósseis para os quais as ideias de Freud ainda são última palavra da ciência na explicação da religião, da moral e da sociedade" (p. 77).

Além disso, na década de 1950, a revista publica três resenhas sobre três livros de André Berge (1902-1995), médico, filósofo e licenciado em letras, com diversos livros na área da psicologia da criança e do adolescente (seção de livros 1957, 1958 e 1959). Ou, nas palavras do resenhista: "Dr. Berge, que preocupado com a educação dos próprios filhos, resolveu fazer-se médico e dedicar estudos especiais à psicanalise" (C. F., 1958, p. 80). A resenha de 1957, referente ao livro "Como educar pais e filhos", feita por C. A., é extremamente elogiosa e faz apelo para que todos o leiam. Já na de 1958, sobre o livro "A educação moral e afetiva", os elogios permanecem, mas C. F. critica o profundo apego do autor pela psicanálise, considerada ultrapassada pelo avanço da ciência. Em 1959, em relação ao livro "Os defeitos da criança", C. F. aumenta o volume de críticas, considerando que Berge tem sido "excessivamente fiel ao velho mestre de Viena, parece não ter tomado conhecimento dos estudos mais modernos, que invalidam em parte as teorias freudianas" (1959, p. 71). Embora reconheça que o livro possa prestar bons serviços a pais e educadores "que saibam se prevenir contra um certo materialismo filosófico, próprio do autor", alerta-se que pode ser perigoso para aqueles que, com pouca cultura, não consigam "isolar o joio do trigo" (C.F., 1959, p. 152) - uma distinção que a intelectualidade católica não pode deixar de fazer, entre os que sabem e os que não sabem, entre a elite e os outros.

Parece, pois, que a psicanálise não é bem aceita, seu conhecimento devendo ser restrito àqueles que têm a ilustração necessária para discernir o que é válido ou não em seus postulados.

\section{Consideraçóes finais}

Esta investigação, centrada em uma revista católica que teve grande importância no meio intelectual, não só da instituição religiosa, mas da elite educada do País nas décadas estudadas, aponta como as relaçôes entre ciência e religião são entremeadas por outros fatores, como momentos políticos específicos, presença de lideranças expressivas, circulação de ideias em gestação em outros espaços, etc. Especificamente, vimos como a Igreja Católica aqui entendida como os intelectuais que a representavam em "A Ordem" - de uma posição de rejeição à psicologia (materialista e evolucionista) e do sentimento de ameaça de perda de seu poder de "educar as almas", consegue perceber as transformaçôes desse campo e observar formas emergentes - como a Psicologia humanista - que se coadunam com seu modo de ver o homem. Assim, conciliaçóes são possíveis, embora o controle institucional deva ser mantido. Daí a importância da criação dos cursos de psicologia nas universidades católicas como forma de manutenção de seu objetivo de educar as elites e, principalmente, cuidar das almas.

\section{Referências}

Aguiar, R. C. (2000). O rebelde esquecido: Tempo, vida e obra de Manoel Bomfim. Rio de Janeiro: Topbooks.

Athayde, T. (1932). O Instituto Oficial de Psicologia. A Ordem, 13(6), 401-407.

Athayde, T. (1934). Traços da psychologia do povo brasileiro. A Ordem, 14(48), 124-140.

Barbosa, C. F. (1929). O problema da formação do pensamento. A Ordem, 9(4), 152-165.

Barreto Filho. (1941). Uma psicologia humana da educação. A Ordem, 21(1), 37-60.

Berge, F. D. (1939). A estrutura fundamental do sentimento religioso à luz da psicologia experimental. A Ordem, 21, 125-150.

C. A. (1957). André Berge: Como educar pais e filhos? A Ordem, 58(6), 494-496.

C. F. (1958). André Berge: A educação sexual e afetiva. A Ordem, 59(2), 180-181.

C. F. (1959). André Berge: Os defeitos das crianças. A Ordem, 59(2), 151-152.

Câmara, H. (1934). A psychologia da fé. A Ordem, 14(53), 64-65.

Caminha, P. V. (1500). A Carta. Acesso em 15 de junho de 2013, em http://www.dominiopublico. gov.br/download/texto/ua000283.pdf

Cannabrava, E. V. (1934). Será a Psychologia Sciencia natural ou cultural. A Ordem, 14(51), 345-359.

Carvalho, J. M. (1987). Os bestializados. São Paulo: Companhia das Letras. 
Carvalho, J. M. (1990). A formação das almas - o imaginário da República no Brasil. São Paulo: Companhia das Letras.

Centofanti, R. (1982). Radecki e a Psicologia no Brasil. Psicologia, Ciência e Profissáo, 1, 3-50.

Centro de Pesquisa e Documentação de História Contemporânea do Brasil (S.D). A Era Vargas. Acesso em 02 de Fevereiro de 2014, em http:// cpdoc.fgv.br/producao/dossies/AEraVargas 1/ anos37-45/EducacaoCulturaPropaganda/PUC

Dumont, L., (1985). O individualismo - uma perspectiva antropológica na ideologia moderna. Rio de Janeiro: Rocco.

Fausto, B. (1995). História do Brasil. São Paulo: Edusp/FDE.

Ferraz, D. P. A. (2014). Memórias e Histórias do Curso de Psicologia da Faculdade Salesiana de Lorena/SP: uma contribuição para a historiografia da Psicologia no Brasil. Tese de Doutorado, Universidade Estadual do Rio de Janeiro, Rio de Janeiro.

Franca, L. (2001). A psicologia da fé. Rio de Janeiro: Ed. PUC-Rio/Loyola. (Original publicado em 1934).

Freyre, G. (2000). Casa Grande \& Senzala: Introdução à história da sociedade patriarcal no Brasil. (48 $\mathrm{Ed}$.). São Paulo: Global Editora. (Original publicado em 1933).

Holanda, S. B. (1969). Raizes do Brasil (5a Ed.). Rio de Janeiro: José Olympio. (Original publicado em 1936).

Jacó-Vilela, A. M. (2012). História da Psicologia no Brasil: uma narrativa por meio de seu ensino. Psicologia: Ciência e Profissão, 32, 28-43.

Lobato, J. H. V. (2013). Entre a oração e o trabalho. $O$ estudo de Psicologia no Mosteiro de Sáo Bento do Rio de Janeiro entre 1930 e 1950. Tese de Doutorado. Universidade do Estado do Rio de Janeiro, Rio de Janeiro.

Lourenço Filho, M. B. (2001). Introdução ao estudo da Escola Nova: (18 ${ }^{\mathrm{a}}$ Ed.). Rio de Janeiro: Editora da UERJ. (Original publicado em 1930).

Lourenço Filho, M. B. (2004). A Psicologia no Brasil. In M. A. P. Antunes, História da psicologia no Brasil: primeiros ensaios (pp. 109-119). Rio de Janeiro: Editora da UERJ. (Original publicado em 1955).

Massimi, M. (1990). História da Psicologia Brasileirada época colonial até 1934. São Paulo: E.P.U.
Massimi, M. (2000). A discussão sobre Psicologia Científica e Educação na Revista A Ordem, de 1930 a 1945. Cadernos de Psicologia (UFMG), 9, 69-84.

Massimi, M. (2007). O processo de institucionalização do saber psicológico no Brasil do século XIX. In: A. M. Jacó-Vilela, A. A. L. Ferreira, \& F. T. Portugal (Eds.), História da psicologia: rumos e percursos. Rio de Janeiro: NAU.

Mendieta, E., \& Van Antwerpen, I. (2011). El poder de la religión en la esfera pública. Madrid: Ed. Trotta.

Morais Jr., A. D’A. (1943). A doutrina de Freud. A Ordem, 29, 260-262.

Nery, J. C. (1935). Possessão, histeria e êxtase. A Ordem, $8,328-335$.

Nogueira, H. (1921). As curas milagrosas de Lourdes à luz da medicina. A Ordem, 1(3), 41-42.

Prado Jr., C. (1989). Formaçâo do Brasil (21 a ed.). São Paulo: Ed. Brasiliense. (Original publicado em 1942).

Ramos, A. (1932). A possessão fetichista na Bahia. Archivos do Instituto Nina Rodrigues, 1(2), 30-32.

Romero, S. (1926). Explicaçôes indispensáveis. Prefácio a Vários Escritos de Tobias Barreto de Menezes In T. Barreto, Obras Completas (Vol. 10, pp. i-xxvi). Sergipe, Brasil: Empreza Graphica Editora. (Original publicado em 1900).

Sanchis, P. (2005). A Igreja Católica no Brasil e a dimensão do "sujeito". In L. F. D. Duarte, J. Russo \& A. T. Venâncio (Eds.), Psicologização no Brasil: atores e autores. Rio de Janeiro: Contra Capa.

Sanchis, P. (2012) O "som Brasil" - uma tessitura sincrética? In M. Massimi (Ed.), Psicologia, cultura e história: diálogos em perspectivas. Rio de Janeiro: Outras Letras.

Santos, L. J. (1930). Santo Agostinho: suas ideias em pedagogia e psychologia. A Ordem, 10(9), 103-111.

Santos, T. M. (1935). Aspectos da Psicologia do Sonho. A Ordem, 15(1), 346-355.

Santos, T. M. (1938a). A Educação e as tendências atuais da Psicologia. A Ordem, 20, 126-151.

Santos, T. M. (1938b). O problema da gênese do sonho. A Ordem, 20, 361-366.

Santos, T. M. (1939). O sonho e a memória. A Ordem, $22,12-37$.

Santos, T. M. (1940a). Os fatores orgânicos e a gênese do sonho. A Ordem, 23, 251-276.

Santos, T. M. (1940b). Psicologia comparada do sonho e da criança. A Ordem, 22, 521-530. 
Schincariol, M. T. (2006). Catolicismo, Romance Católico e Crítica Literária no Contexto da Revista A Ordem. Revista de Estudos da Religião, 4, 96-124. Acesso em 04 de Maio de 2013, em http://pucsp. br/rever/rv4_2006/p_schincariol.pdf

Serbin, K. P. (2008). Padres, celibato e conflito social: uma história da Igreja Católica no Brasil. São Paulo: Cia. das Letras.

Velloso, M. P. (1978). A Ordem: Uma revista de doutrina, política e cultura católica. Revista Ciência Política, 21(3), 117-160.

Villaça, A. C. (2006). O pensamento católico no Brasil. Rio de Janeiro: Civilização Brasileira.

\section{Endereço para correspondência:}

Ana Maria Jacó-Vilela

Programa de Estudos e Pesquisas em História da Psicologia - Núcleo Clio-Psyché - Universidade do Estado do Rio de Janeiro

Rua Sáo Francisco Xavier, 524, $10^{\circ}$ andar, bloco F, sala 10120 - Maracanã

CEP 20559-900 - Rio de Janeiro/RJ

E-mail:amjaco@uol.com.br

Recebido em 31/07/2013

Revisto em 27/02/2014

Aceito em 28/02/2014

* Apoio financeiro: Conselho Nacional de Desenvolvimento Científico e Tecnológico (CNPq) e Fundação de Amparo à Pesquisa do Estado do Rio de Janeiro (FAPERJ). 